\title{
ANALYSIS OF LOADS AND STRUCTURAL CAPACITY OF STEEL SILO WITH CORRUGATED WALL FOR PELLETED MATERIAL
}

\author{
Ryszard ANTONOWICZ, Czesław BYWALSKI, Mieczysław KAMIŃSKI \\ Institute of Building Engineering, Wrockaw University of Technology, \\ pl. Grunwaldzki 11, 50-377 Wrockaw, Poland
}

Received 25 Jul 2013; accepted 19 Nov 2013

\begin{abstract}
This paper deals with problems connected with the design and operation of thin-walled steel silos for storing pelleted materials. A failure of a faultily designed silo is described and its causes are examined. The parameters of the stored material were determined. The exceptional (unforeseen) loads produced by arching and their consequences were analysed. In order to compare the effect of calculation assumptions on the degree of use of the load-bearing capacity of the stringer its buckling capacity under the stored material load alone was checked. On the basis of the analyses the probable course of the events leading to the failure was determined. It is pointed out that the exceptional loads and the disturbance of the bulk material flow by silo structural and technological fittings need to be taken into account in the design of silos.
\end{abstract}

Keywords: silos, failure, accidental load, stability, flow disturbances.

Reference to this paper should be made as follows: Antonowicz, R.; Bywalski, C.; Kamiński, M. 2014. Analysis of loads and structural capacity of steel silo with corrugated wall for pelleted material, Journal of Civil Engineering and Management 20(3): 372-379. http://dx.doi.org/10.3846/13923730.2014.906497

\section{Introduction}

The constant tendency towards silo construction cost reduction results in the use of increasingly thinner metal sheets and profiles. Moreover, new materials, often with insufficiently identified physical properties, such as pelleted biomasses, are stored in silos. Consequently, the walls, bottoms and hoppers of the silos are subjected to greater bulk material impacts than the design ones. Because of the static behaviour of thin-walled steel silos such damage as deformations of the edges of the joined sheets, loss of leak tightness, hole ovalization, deformations of the compliant silo shell caused by differential pressures connected with aeration and discharging, etc. arises. Most of the above problems are not covered by the silo design standards. Some of them are included in the standards for the design of thin-walled steel structures (EN 1993-1-3 2006). Valuable design information can be found in scientific and technical papers. Silo research results are most exhaustively reported in Rotter (2001) and Sadowski and Rotter (2010, 2011, 2012). Researches of Brown and Nielsen (1998) and Gallego et al. (2011) are also devoted to the design of silos. Also, Ding et al. (2013) reported predictions and experiments of pressures in silos.

Since the problems relating to the flow of particulate solids are complex, failures of silos, especially the thinwalled ones, continue to occur. This paper discusses the problems connected with the design and operation of thin-walled steel silos for pelleted materials. The discussion is based on a case study of a failed silo.

\section{Bolted thin-walled silos}

Thin-walled silos made from bolted corrugated sheets are designed and built in two versions: with an unbraced chamber wall and with the chamber wall braced with a system of vertical or vertical and horizontal sections (posts or rings). The former type of structure is typical for squat small-volume silos while the latter is typical for tall and slender silos, often grouped into batteries.

The storage of materials characterized by high cohesion and a tendency to agglomeration in such silos and the insufficient identification of the properties of the stored materials often lead to structural failures (usually during discharging). The shearing of the connectors at the contact between the segments and the stringers as a result of the dynamic collapse of an arch is an example of such a failure. The collapse of an arch may also result in underpressure in the silo's upper part when there are no or not enough aeration vents. This quite often results in the collapse of the walls and the roof into the silo chamber.

In hopper silos the rapid increase in vertical pressure accompanying arch removal often results in the breaking off of the hopper. Also cases of material flowing out through circumferential gaps in the horizontal contact between the segments joined with connectors spaced too widely have been reported. During discharging the increase in pressure, the asymmetric patch load pressure and the frictional tracking pressure may result in the squeezing out of the material through the horizontal contacts between the segments. 
The silo studied in this paper (Fig. 1) has a $21.00 \mathrm{~m}$ high cylindrical chamber $9.17 \mathrm{~m}$ in diameter, made from 2 and $3 \mathrm{~mm}$ thick corrugated S270GD and Z275 steel sheets. Vertically the silo is made up of 21 segments. The topmost segment is equipped with explosion doors. The wall skin sheeting can bear loads latitudinally.

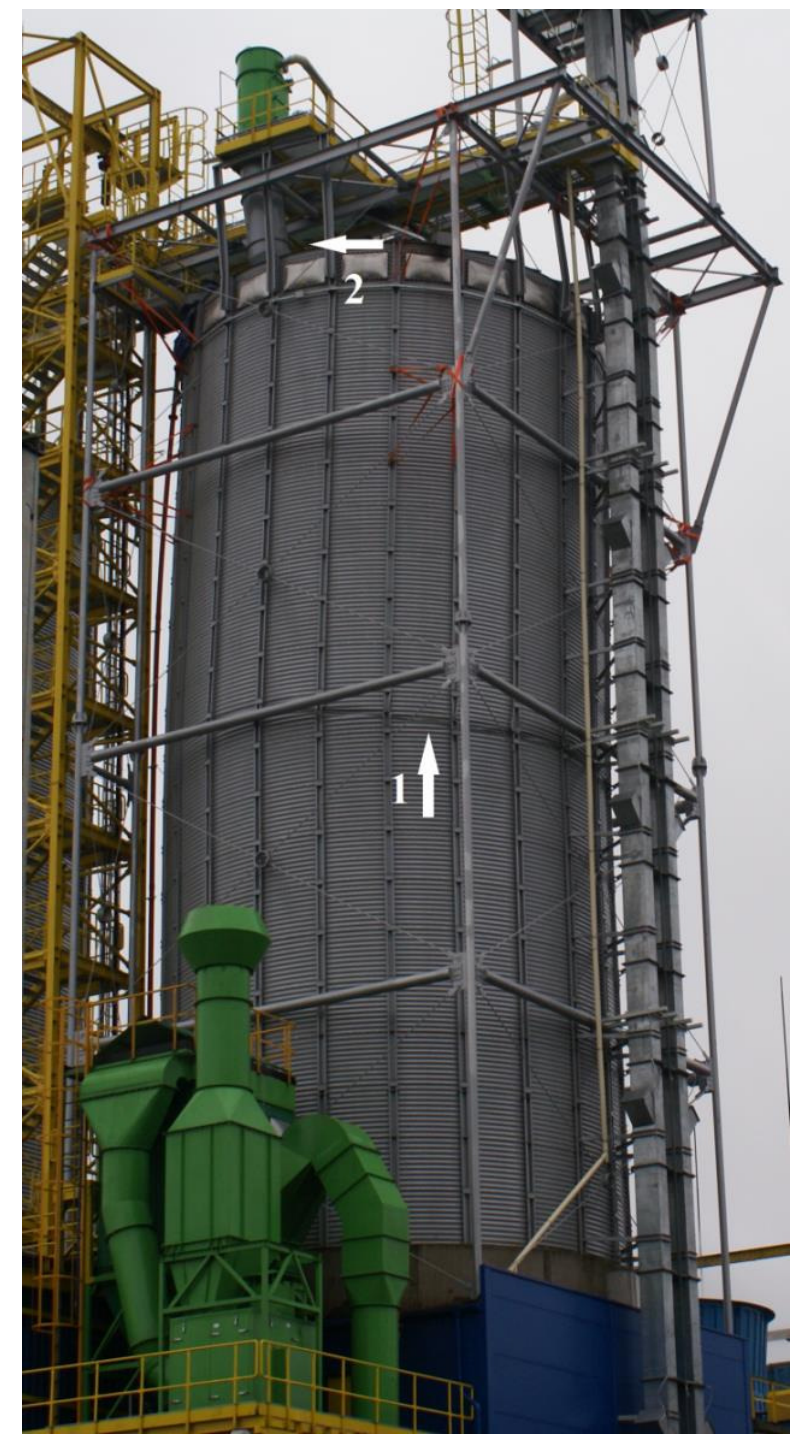

Fig. 1. Silo after failure: 1 - one-sided deformation of tens $\mathrm{cm}$ wide band of ribbed shell; 2 - displaced upper part of cylinder and broken joint between shell and gallery (tilting of silo)

In the meridional direction the load is carried by vertical stringers with a top hat cross section, made from cold bent profiles. In total there are 22 stringers shifted by an angle of $16.36^{\circ}$ along the chamber's circumference. The upper stringers are made from $2 \mathrm{~mm}$ thick sheets and the lower ones from 3 and $4 \mathrm{~mm}$ thick sheets. The cylindrical shell of the silo rests on a reinforced concrete ring monolithically connected with the bottom in the shape of a truncated cone with its side surface inclined at an angle of $39^{\circ}$ to the vertical. The bottom has a diameter of $6000 \mathrm{~mm}$. There is an eccentrically located (the eccentricity relative to the centre amounting to about $1 \mathrm{~m}$ ) discharge slit in the bottom. Silo discharging is aided by a screw conveyor placed in the discharge slit and by a rotor sweeping the pelleted material into the slit. Relief plate girder beams located above the rotor provide a shield for the discharge aiding mechanism. They relieve the bottom and the equipment, but at the same time they significantly disturb the flow of the pelleted material.

The silo is covered with a lightweight roof in the shape of a truncated cone with its element inclined by an angle of $30^{\circ}$ to the horizontal. The silo is centrically charged through a hole in the roof.

The studied silo, together with a neighbouring silo (identical in design) for storing wood chips, is founded on a reinforced concrete building structure. Next to the silos there is a truss structure serving as a support for the bucket conveyors transporting the pelleted material to the upper charging gallery.

\section{Properties of stored material}

In the literature on the subject (Jensen et al. 2004; Mattsson 1990) one can find much information on the properties of pelleted biomass used for producing energy (through combustion or co-combustion), but usually these are the properties having a bearing on the combustion process and its effects.

During transport and storage each kind of pelleted material is subjected to mechanical impacts and most importantly, its moisture content changes. The latter parameter determines the pelleted material transport, storage and processing costs. It is also a major factor having a bearing on the price of the pelleted material. High moisture content lowers the calorific value of the pelleted material, reduces the output of the equipment (mills), lowers the combustion temperature and adversely affects the temperature distribution in the combustion chamber. In contrast to this, dry biomass accelerates ignition and intensifies combustion in the combustion chamber.

Larsson et al. (2012) reported large scale silo experiments. The temperature patterns were observed during 7 month period. Occasionally, pellet temperature increased vertically from bottom to top and temperatures were increasing uncontrollably. Maximum temperature increment of $2.4^{\circ} \mathrm{C} / \mathrm{h}$ was found.

Moist pelleted materials have a tendency towards caking and arching, which considerably disturbs their flow in the silo. The moisture content of the pelleted material also affects the lateral pressure ratio (Hotała, Kuśnierek 2013).

The mechanical and chemical properties of agricultural wastes have been studied by, among others, by Skonecki et al. (2011a, b), Fernández et al. (2013), Horabik (2001) and Jensen et al. (2004). The latter author studied the caking and arching of wood pellets. Also Miccio et al. (2013) estimated solid biofuel flowability and critical diameter of orifice using new procedure derived from Jenike's arch stability analysis.

Oveisi et al. (2013) tested the mass loss of pellets due to free fall. They reported increase of the percentage of dust each drop and accumulation of fines after five drops.

Chen et al. (2012) used Jenike's procedure to compare flowability of fuel powders (sawdust, brown coal 
and hard coal). Sawdust was classified as easy flowing at low consolidation stress.

The reliability levels of the determined properties vary widely depending on the kind of pelleted material and its quality. The biomass combustion facilities in electric power plants and in heat and power plants have been designed for a wide range of biomasses, considerably differing in their physicomechanical properties. Because of the lack of clearly defined biomass parameters designers use their estimates, which, in their opinion, guarantee the safety of the structure. In the considered case, the designer instead of the properties of the pelleted material, assumed the properties of wheat as a heavier material, without paying attention to the effect of the other properties on the component pressures and completely neglecting exceptional loads, especially the caking of the pelleted material and arching, and the effect of the relief beams on the standard dependences for the variation in bulk material pressure along the wall height.

\section{Bulk material load}

Silo pressure on vertical walls after the silo has been filled can be calculated from the Eqns presented in Eurocode 1 Part 4 (2006). The silo is classified as a slender silo $\left(h_{c} / d_{c}>2\right)$ in Action Assesment Class $2\left(e_{o} / d_{c}<0.25\right)$.

Evaluation of the wall friction coefficient for a sinusoidal corrugated wall is determined as:

$$
\begin{aligned}
& \mu_{\text {eff }, u}=\left(1-a_{w}\right) \cdot \tan \varphi_{i, u}+a_{w} / \mu_{w} ; \\
& \mu_{\text {eff }, l}=\left(1-a_{w}\right) \cdot \tan \varphi_{i, l}+a_{w} / \mu_{w},
\end{aligned}
$$

where: $\mu_{\text {eff }, u}$ - the effective wall friction coefficient (upper); $\mu_{e f f, l}$ - the effective wall friction coefficient (lower); $\phi_{i, u}$ - the angle of internal friction (upper); $\phi_{i, u}$ - the angle of internal friction (lower); $\mu_{w}$ - the wall friction coefficient against a flat surface; $a_{w}$ - the wall contact factor $\left(a_{w}=0.2\right)$.

The geometric characteristics of the silo determined in accordance with Figure 1 in the Eurocode 1 Part 4 (2006) and the properties of the stored material are presented in Table 1. The loads calculated for the above assumptions are shown in Figures 2 and 3.

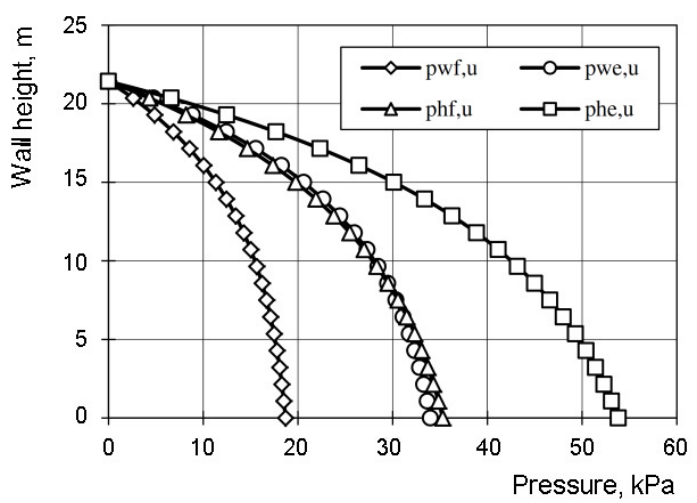

Fig. 2. Diagrams of symetrical and patch load pressures (for filling and discharging) in the vertical silo wall

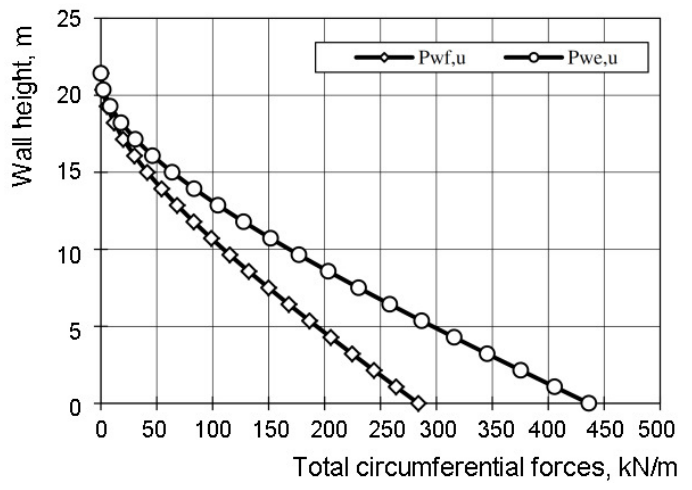

Fig. 3. Diagrams of total circumferential forces (for filling and discharging) in the silo wall

\begin{tabular}{|c|c|c|c|}
\hline Description & Symbol & Unit & Value \\
\hline $\begin{array}{l}\text { Plan cross-sectional area of } \\
\text { vertical walled segment }\end{array}$ & A & {$\left[\mathrm{m}^{2}\right]$} & 66.33 \\
\hline $\begin{array}{l}\text { Internal perimeter of the plan } \\
\text { cross section of the vertical } \\
\text { walled segment }\end{array}$ & $\mathrm{U}$ & {$[\mathrm{m}]$} & 28.87 \\
\hline $\begin{array}{l}\text { Height from the transition do } \\
\text { the equivalent surface }\end{array}$ & $\mathrm{h}_{\mathrm{c}}$ & {$[\mathrm{m}]$} & 21.43 \\
\hline Unit weight of bulk material & $\gamma$ & {$\left[\mathrm{kN} / \mathrm{m}^{3}\right]$} & 5.77 \\
\hline Equivalent diameter & $d_{c}$ & {$[\mathrm{~m}]$} & 9.19 \\
\hline Hopper inclination angle & $\beta$ & {$\left[{ }^{\circ}\right]$} & 39 \\
\hline $\begin{array}{l}\text { Hopper height from the bottom } \\
\text { to the transition }\end{array}$ & $\mathrm{h}_{\mathrm{h}}$ & {$[\mathrm{m}]$} & 1.50 \\
\hline $\begin{array}{l}\text { Coefficient of friction against } \\
\text { hopper }\end{array}$ & $\mu_{\mathrm{i}}$ & {$[-]$} & 0.30 \\
\hline $\begin{array}{l}\text { Coefficient of friction against } \\
\text { wall (upper) }\end{array}$ & $\mu_{\text {eff,g }}$ & {$[-]$} & 0.61 \\
\hline $\begin{array}{l}\text { Coefficient of friction against } \\
\text { wall (lower) }\end{array}$ & $\mu_{\mathrm{eff}, \mathrm{d}}$ & {$[-]$} & 0.51 \\
\hline Pressure ratio & $\mathrm{K}_{\mathrm{m}}$ & {$[-]$} & 0.45 \\
\hline Discharge eccentricity & $\mathrm{e}_{\mathrm{o}}$ & {$[\mathrm{m}]$} & 1.0 \\
\hline Load factor & $\gamma_{\mathrm{Q}}$ & {$[-]$} & 1.5 \\
\hline
\end{tabular}

Table 1. Calculation assumptions

\section{Additional pressures not covered by standards}

The possibility of arching according to the Walker hypothesis (Walker 1966) and the negative pressure produced by the removal of an arch (Hotała 2003) were analyzed. Calculations, according to Nothdurft (1975), for the additional pressure over the relief beams were performed.

The assumptions made for the calculations according to the Walker (1966) hypothesis are illustrated in Figure 4.

It is assumed that in the place where arching occurs additional pressure acts on the walls, which is expressed by the Eqn (3):

$$
p_{R}=\frac{D \cdot \gamma_{o}}{(1+m) \cdot \sin 2 \delta}
$$

where: $m=1$. 


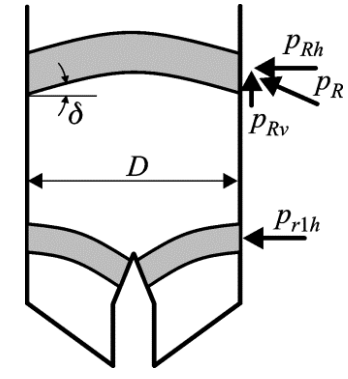

Fig. 4. Assumptions for calculation of pressure generated by arching

Angle $\delta$ cannot be precisely determined without carrying out experiments. Therefore Table 2 shows results for different values of $\delta$. The horizontal and vertical pressure components are expressed by the Eqns:

$$
\begin{gathered}
p_{R h}=p_{R} \cdot \cos \delta ; \\
p_{R v}=p_{R} \cdot \sin \delta .
\end{gathered}
$$

Table 2. Impacts produced by arching

\begin{tabular}{c|c|c|c}
\hline $\begin{array}{c}\text { Angle } \delta \\
{\left[{ }^{\circ}\right]}\end{array}$ & $\begin{array}{c}p_{R} \\
{[\mathrm{kN} / \mathrm{m}]}\end{array}$ & $\begin{array}{c}p_{R h} \\
{[\mathrm{kN} / \mathrm{m}]}\end{array}$ & $\begin{array}{c}p_{R v} \\
{[\mathrm{kN} / \mathrm{m}]}\end{array}$ \\
\hline 2 & 592.85 & 592.49 & 20.69 \\
5 & 238.15 & 237.25 & 20.76 \\
10 & 120.91 & 119.08 & 21.00 \\
15 & 82.71 & 79.89 & 21.41 \\
20 & 64.34 & 60.46 & 22.00 \\
25 & 53.99 & 48.93 & 22.82 \\
30 & 47.75 & 41.36 & 23.88 \\
\hline
\end{tabular}

Hotała (2003) analysed the loads generated in the silo by a bulk material column moving after the removal of an arch. The assumptions made for the analysis are shown in Figure 5.

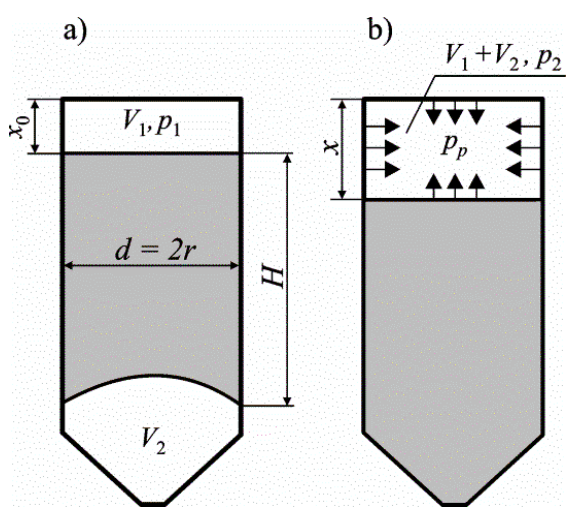

Fig. 5. Assumptions made for calculation of impacts produced by arch removal, according to Hotała (2003): a) situation before arch removal; b) situation after arch removal

In accordance with the above assumptions one can calculate the negative pressure generated in the upper part of the silo chamber cylinder:

$$
p_{p}=k_{o}\left(p_{a}-p_{1} \frac{x_{0}}{x}\right)
$$

where: $k_{o}-$ a coefficient taking into account the presence of aeration vents; $k_{o}=0$ - aeration vents ensure $100 \%$ pressure equalization; $k_{o}=1-$ no pressure equalizing vents.

The additional pressures in a silo equipped with relief beams can be calculated from the relations developed by Nothdurft (1975). The additional vertical pressure is expressed by:

$$
p_{v o}=\frac{\gamma \cdot D}{\mu_{o} \cdot \lambda_{o} \cdot 4},
$$

where: $\gamma$ - the weight density of the material; $D-$ the diameter of the silo; $\mu_{o}$ - the coefficient of friction against the wall; $\lambda_{o}$ - the pressure ratio.

The additional horizontal pressure can be calculated from the Eqn (8):

$$
p_{h o}=\lambda_{o} \cdot p_{v o} .
$$

The pressures in the silo, including the additional pressures calculated from Eqns (7) and (8), are shown in Figure 6.

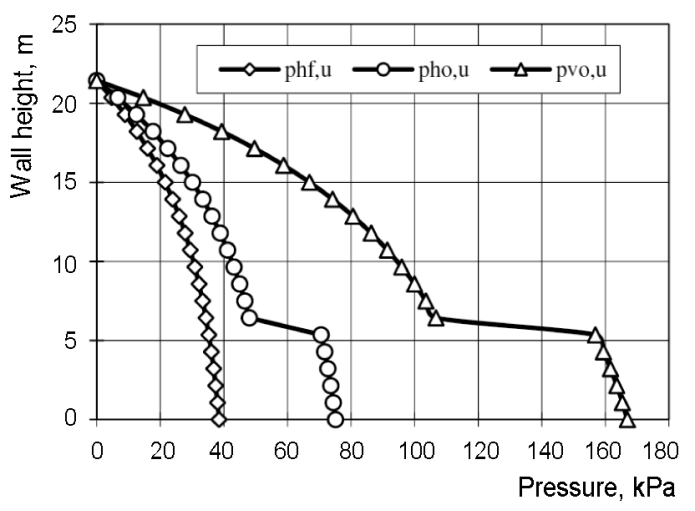

Fig. 6. Horizontal pressures during charging $\left(p_{h f, u}\right)$, discharging $\left(p_{h o, u}\right)$, and vertical pressure $\left(p_{v o, u}\right)$ in silo with effect of relief beams taken into account

\section{Properties of pelleted material removed from silo after failure}

In total, 10 samples of the pelleted material were taken from different levels of the chamber that were earlier chosen at a distance of 2.0-2.5 m each. The sample 1 was taken from the top level, while the sample 10 from the lowest one. Every sample was then placed directly in a tight plastic container, in which they remained 24 hours until the time of tests.

The samples were subjected to tests in order to determine their physical and mechanical properties for the purposes of static-strength analyses.

The tests included a determination of moisture content, bulk density, coefficient of friction against sheeting and internal friction angle. The moisture content of the pelleted material was determined with a gravimetric method. Moreover, a sieve analysis was performed and an angle of repose was determined. The test results are presented in Tables 3 and 4.

The pelleted material stored in the silo when the latter failed was highly heterogeneous in its physical properties. The mass percentages of the individual fractions in 
the samples varied greatly. Also a high percentage of fine (below $1 \mathrm{~mm}$ ) fractions was discovered.

Table 3. Moisture content and density of pelleted material samples

\begin{tabular}{c|c|c|c}
\hline $\begin{array}{c}\text { Sample } \\
\text { No. }\end{array}$ & $\begin{array}{c}\text { Moisture content } \\
{[\%]}\end{array}$ & $\begin{array}{c}\text { Bulk density } \\
{\left[\mathrm{kg} / \mathrm{m}^{3}\right]}\end{array}$ & $\begin{array}{c}\text { Consolidated density } \\
{\left[\mathrm{kg} / \mathrm{m}^{3}\right]}\end{array}$ \\
\hline 1 & 11.5 & 408 & 586 \\
2 & 12.7 & 463 & 599 \\
3 & 12.8 & 433 & 582 \\
4 & 13.2 & 455 & 602 \\
5 & 12.6 & 424 & 568 \\
6 & 12.3 & 424 & 575 \\
7 & 11.4 & 430 & 565 \\
8 & 11.9 & 438 & 572 \\
9 & 10.3 & 409 & 544 \\
10 & 11.1 & 469 & 573 \\
\hline
\end{tabular}

Table 4. Coefficient of friction against galvanized sheeting, internal friction angle and angle of repose

\begin{tabular}{c|c|c|c}
\hline $\begin{array}{c}\text { Sample } \\
\text { No. }\end{array}$ & $\begin{array}{c}\text { Coefficient of friction } \\
\text { against sheeting [\%] }\end{array}$ & $\begin{array}{c}\text { Internal friction } \\
\text { angle }\left[{ }^{\circ}\right]\end{array}$ & $\begin{array}{c}\text { Angle } \\
\text { of repose }\left[{ }^{\circ}\right]\end{array}$ \\
\hline 1 & 0.3 & 35 & 44 \\
2 & 0.25 & 31 & 43 \\
3 & 0.25 & 31 & 44 \\
4 & 0.19 & 32 & 40 \\
5 & 0.16 & 33 & 41 \\
6 & 0.16 & 28 & 43 \\
7 & 0.16 & 28 & 42 \\
8 & 0.16 & 32 & 43 \\
9 & 0.16 & 31 & 43 \\
10 & 0.16 & 28 & 41 \\
\hline
\end{tabular}

A large scatter of the values of the angle of repose and the angle of material friction against the galvanized sheeting was observed. The moisture content and the angle of repose exceeded much the permissible values specified in the silo documentation.

\section{Calculations verifying load-bearing capacity of rib (stringer) at failure level and their analysis}

The buckling capacity of the stringer under the stored material alone is checked below. The aim of the calculations was to compare the effect of the particular assumptions on the degree of use of stringer load capacity. The calculations took into account standards EN 1993-4-1 (2007), EN 1993-1-3 (2006) and EN 1993-1-5 (2006).

Elastic modulus $E=210 \mathrm{GPa}$, steel yield point $f_{y}=442 \mathrm{MPa}$ and tensile strength $f_{u}=467 \mathrm{MPa}$ were assumed.

The load-bearing capacity of the rib was calculated assuming that the side surface made of profiled metal sheeting does not transfer the longitudinal force, but constitutes the support of the rib. The stiffness of the sheathing was taken into account for rib bending perpendicular to the wall. The membrane stiffness of the sheeting is described by the expression:

$$
c_{y}=E t_{y}=E t\left(1+\frac{\pi^{2} d^{2}}{r l^{2}}\right),
$$

where: $E$ - the elastic modulus; $d$ - the height of the profiled sheet; $l$ - the width of the corrugation (the length of the wave); $t$ - the thickness of the profiled sheet (Fig. 7).

The plate stiffness of the sheet is given by the Eqn (10):

$$
D_{y}=E I_{y}=0.13 E t d^{2} .
$$

For $d=15 \mathrm{~mm}, l=100 \mathrm{~mm}$ and $t=2 \mathrm{~mm}, c_{y}=$ $443316940 \mathrm{~N} / \mathrm{m}$ and $D_{y}=12285 \mathrm{Nm}$ were obtained.

Using Eqns (9) and (10) the maximum spacing of the stringers at which the shell can be considered to be orthotropic was determined:

$$
d_{s, \max }=k_{d x}\left(\frac{r^{2} D_{y}}{C_{y}}\right)^{0.25},
$$

where: $r$ - the radius of the silo chamber $(r=4.585 \mathrm{~m})$; $k_{d x}-$ a coefficient whose value recommended by EN 1993-4-1 (2007) amounts to 7.4.

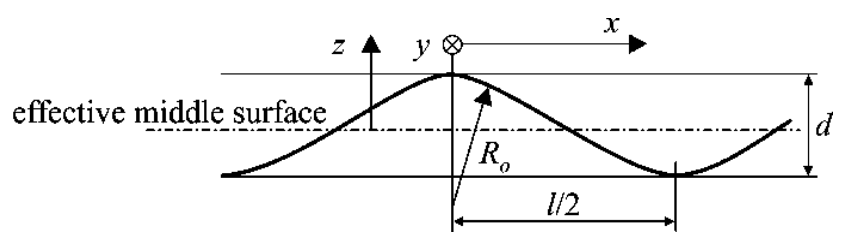

Fig. 7. Cross section of corrugation and geometric parameters of profiled sheet

The spacing calculated from Eqn (11) amounts to $1.15 \mathrm{~m}$. The actual spacing of the stringers (ribs) is larger, amounting to $1.31 \mathrm{~m}$. Thus a shell made of the profiled sheeting cannot be considered as a stiffened wall. It can be assumed that the side surface of the profiled sheeting does not transfer the longitudinal force, but it constitutes a support for the rib.

The buckling capacity of the rib is expressed by the Eqn (12):

$$
N_{b, R d}=\min \left(2 \frac{\sqrt{E I_{y} K}}{\gamma_{M 1}}, \frac{A_{e f f} f_{y}}{\gamma_{M 1}}\right),
$$

where: $E I_{y}$ - the bending stiffness of the rib in the plane perpendicular to the wall $\left(\mathrm{Nmm}^{2}\right) ; K$ - the bending stiffness of the sheathing between the meridional stringers (ribs), according to Eqn (13); $A_{\text {eff }}$ - the effective cross section of the rib; $f_{y}$ - the yield point of the steel; $\gamma_{M I}-\mathrm{a}$ partial coefficient relative to the load capacity $\left(\gamma_{M I}=1.1\right)$.

$$
K=k_{s} \frac{D_{y}}{d_{s}^{3}},
$$

where: $k_{s}$ - a coefficient whose value recommended by EN 1993-4-1 (2007) amounts to 6.0; $D_{y}$ - the bending (plate) stiffness of the sheathing under circumferential bending, according to Eqn (10); $d_{s}$ - the actual spacing of the ribs $\left(d_{s}=1.31 \mathrm{~m}\right)$ (Fig. 8).

The bending stiffness of the sheathing between the meridional stringers calculated from Eqn (13) is $K=$ $32788 \mathrm{~N} / \mathrm{m}^{2}$. 


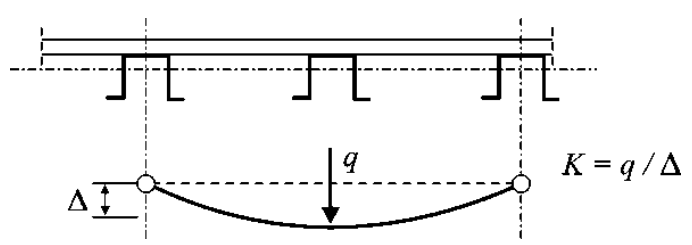

Fig. 8. Determination of sheathing stiffness at rib buckling

Figure 9 shows the actual cross section of the stringer (rib) for which the geometric characteristics (crosssectional area $A_{c}=622.1 \mathrm{~cm}^{2}$, moment of inertia $I_{y}=$ $638160 \mathrm{~mm}^{4}$ ) were calculated.

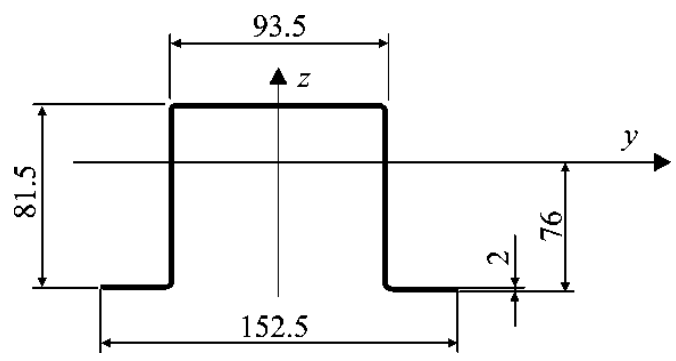

Fig. 9. Actual cross section of rib

Effective area (effective cross section) $A_{\text {eff }}$ of the stringer was determined according to the procedure specified in EN 1993-1-5 (2006). The area is expressed by Eqn (14). It amounts to $477.4 \mathrm{~mm}^{2}\left(A_{\text {eff }}=477.4 \mathrm{~mm}^{2}\right.$ ).

$$
A_{c, e f f}=\rho A_{c},
$$

where: $\rho-$ a reduction coefficient taking into account the instability of the stringer cross section wall (for the cantilever walls of the analysed cross section $\rho=0.748$, for the span walls (webs) $\rho=0.800$, and for the span walls (flanges) $\rho=0.725) ; A_{c}-$ the actual cross section.

By substituting the calculated auxiliary quantities into Eqn (12) one gets $N_{b, R d}=\min (119.08 \mathrm{kN}$, $191.83 \mathrm{kN})=119.08 \mathrm{kN}$. This is the maximal longitudinal force which the stringer can carry.

Table 5 shows the use of the load-bearing capacity of the stringers at the level where the failure occurred. In the calculations of the forces generated in the stringer by the pelleted material stored in the silo the material's actual properties determined in the laboratory were taken into account.

Table 5. Use of stringer load capacity

\begin{tabular}{c|c|c|c}
\hline Case & $\begin{array}{c}\text { Longitudinal force } \\
\text { in stringer (rib), } \\
\mathrm{kN}\end{array}$ & $\begin{array}{c}\text { Buckling capaci- } \\
\text { ty of stringer, } \\
\mathrm{kN}\end{array}$ & $\begin{array}{c}\text { Coefficient of } \\
\text { use of stringer } \\
\text { load capacity }\end{array}$ \\
\hline 1 & 166.02 & & 1.39 \\
2 & 138.08 & 119.08 & 1.16 \\
3 & 198.20 & & 1.66 \\
\hline
\end{tabular}

Cases from 1 to 3 in Table 1 apply to:

1 - the design force produced in the stringer by the load of the pelleted material during the discharging of the chamber, calculated according to EN 1991-4 (2006);
2 - the design force produced in the stringer by the pelleted material during the discharging of the chamber, calculated according to PN-B-03262 (2002);

3 - the force produced in the stringer, with arching taken into account according to Nothdurft (1975).

The buckling load capacity of the silo's vertical stringers is exceeded even for solely the vertical load generated by the material stored in the silo.

The load capacity exceedance percentage depends on the procedure of determining bulk material loads. The procedures differ between design standards (e.g. EN 19914 2006; PN-B-03262 2002). The percentage also depends on whether and to what degree the current state of knowledge relating to exceptional material loads (e.g. arches) and to the contribution of silo fittings (e.g. relief beams) to the disturbance of the flow of the bulk (pelleted) material, especially during discharging, is taken into account.

The smallest load capacity exceedance, amounting to $16 \%$, was obtained for the pelleted material loads determined acc. to Polish standard PN-B-03202 (1996).

A larger load capacity exceedance, amounting to $39 \%$, caused by the bulk (pelleted) material alone during discharging was obtained for the loads determined acc. to EN 1991-4 (2006).

The load capacity exceedances calculated taking into account the permanent loads of the roof catwalk and the technological equipment and climatic loads are larger. But, in the authors' opinion, they are not large enough for a failure to occur (there is a load capacity margin resulting from the use of partial safety factors).

The largest load capacity exceedance, amounting to as much as $66 \%$, was found for the arching load.

If the other loads (e.g. the dead load, climatic loads, technological loads) are taken into account, the load capacity is exceeded even more. A further increase in the strain of the stringers occurs when the additional bending moment $\Delta M_{y, E D}$ caused by a shift in the centre of gravity of the interacting cross section is taken into account.

\section{Probable course of events and causes of failure}

The probable course of events which led to the failure was as follows. The silo was filled with the pelleted material with a highly varying moisture content and a very high dust fraction content (as much 75\%). In the course of storage chemical reactions were taking place in the pelleted material, resulting in its local caking. During discharging a full or partial (an overhang on the wall) arch formed. As a result of subsequent normal charging and discharging a void formed under the arch. Then additional arches formed during discharging. Moreover, the level sensor failed and the silo was overfilled. As the arch was being removed negative pressure was produced below the failure level, the support conditions changed, the load capacity of the stringers was exceeded and as a result of the plastic yielding of the stringers the upper part of the silo shifted downwards. Ultimately, the failure process was stopped as the shell displacements were 
blocked by the horizontal pressure of the pelleted material which had moved down in the silo chamber.

The most characteristic damage resulting from the failure is shown in Figure 10.

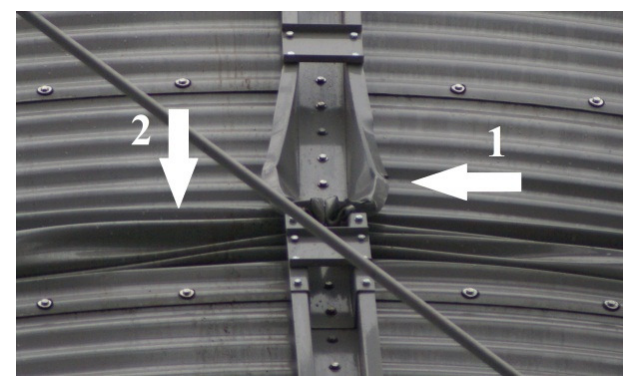

Fig. 10. Most characteristic damage: 1 - damage to stringer; 2 - damage to sheathing (compression of corrugations)

The physicochemical properties of the stored material determined in the laboratory were characterized by a considerable scatter (as large as a few tens of percent). This applies to the moisture content, the weight, the fine (below $1 \mathrm{~mm}$ ) fraction content and the angle of repose. Besides distribution nonuniformity, all the properties significantly exceeded the allowable values specified in the operation and maintenance manual. The exceedance of the allowable values resulted in the arching and caking of the pelleted material, as ascertained after the silo had been discharged.

The relief beams which disturb the gravity flow of the pelleted material are not covered by any design standards. However, from the literature on the subject it appears that their presence results in an increase in the pressure acting on the walls (Nothdurft 1975).

The effect of simultaneous charging and discharging is not taken into account in standard EN 1991-4 (2006).

An analysis of all the combinations of interactions and of the silo design showed that the load-bearing capacity of the stringers was not sufficient in the typical analytical situation, not to mention exceptional situations.

To sum up, it can be stated that an exceptional load produced by arching, which is not covered by the standards relating to the design of silos, caused the failure. Despite the fact that the silo had been designed for a heavier material (wheat) with bulk density $\gamma=900 \mathrm{~kg} / \mathrm{m}^{3}$, the other properties of the pelleted material stored in it contributed to the occurrence of the exceptional load which does not occur in the case of wheat.

\section{Conclusions}

The design of silos requires from designers having considerable experience and a wider knowledge of the principles of design than the ones encompassed by the standards dealing with the design of silos. From the structure's reliability point of view it is imperative to correctly identify the actions of the bulk solid on the wall shell during the filling, discharge and simultaneous filling and discharge of the silo.

At the same time one should also take into consideration any disturbances in the flow of the stored solid, due to the adopted structural and technological solutions, such as cross-beams in a zone of transition between a shell and a hopper, or a structure protecting the rotor sweeping a solid into an outlet (often having the form of an eccentrically located slit). The cross-beams were used in the analysed silo. They caused an increase in values of standard pressures. For example, the normal pressures in a zone of solid flow disturbances due to the presence of cross-beams increased maximally by $57 \%$ when calculated according to Nothdurft (1975). According to the same author (Nothdurft 1975) the influence of inserts on a change of pressure distribution is observed above the level of cross-beams in the height equal to the silo diameter.

In the case of cohesive biomass one should also examine the effect of its moisture content on such properties as the internal friction angle, the angle of repose and bulk density. In this instance the physical and mechanical properties of the pelleted material were characterised by a significant dispersion. The moisture differed maximally in $28 \%$, bulk density in $15 \%$, internal friction angle in $25 \%$, and the coefficient of friction against sheeting in as much as $88 \%$.

Simultaneously one should also consider a possibility of forming of an arch in the silo chamber, which entails an exceptional state of loading that is not quantitatively formulated in the relevant design standards. In this case the sum of frictional loads in the level of failure caused by an aching was exceeded by $80 \%$ in comparison with the value of standard discharge pressures.

In the authors' opinion, the considered silo failed as a result of an arch which had formed at the level where the failure occurred. Among all the examined loads of the bulk solid on the walls of the silo chamber the case of arching has proven to exceed the limit state of stringers most of all (by 66\%).

The operational experience relating to silos for storing pelleted materials indicates that in order to minimize the risk of caking and arching it is necessary to determine the limit moisture content values for pelleted materials, their angle of repose and the maximum time of their "immobility". Such parameters should be issued to the investor by the designer in the form of operational guidelines. In the present instance the moisture content and angle of repose were significantly greater than the permissible limit specified in the silo documentation. As far as the angle of repose is concerned, its experimentally determined value $\left(40-44^{\circ}\right)$ was up by $67-83 \%$ greater than the permissible limit specified in the silo documentation $\left(24^{\circ}\right)$. These facts must be associated with both the $25 \%$ higher than expected moisture content of the pellets and a considerable percentage share of the fine fraction, less than $1 \mathrm{~mm}$ (in some samples more than $50 \%$ ). These factors combined with a very long time of "immobility" of the pellets in the chamber (for 4 days) led to forming the arch.

\section{References}

Brown, C. J.; Nielsen, J. (Eds.). 1998. Silos: fundamentals of theory, behaviour and design. E\&FN Spon. 856 p. http://dx.doi.org/10.4324/9780203223512 
Chen, P.; Yuan, Z.; Shen, X.; Zhang, Y. 2012. Flow properties of three fuel powders, Particuology 10(4): 438-443. http://dx.doi.org/10.1016/j.partic.2011.11.013

Ding, S.; Rotter, J. M.; Ooi, J. Y.; Enstad, G.; Xu, D. 2013. Normal pressures and frictional tractions on shallow conical hopper walls after concentric filling: predictions and experiments, Chemical Engineering Science 89: 264-272. http://dx.doi.org/10.1016/j.ces.2012.11.028

EN 1993-1-3: 2006 - Eurocode 3: Design of steel structures Part 1-3: General rules - Supplementary rules for coldformed members and sheeting. Brussels: European Committee for Standardization (CEN), 2006. $133 \mathrm{p}$.

EN 1993-1-5: 2006 - Eurocode 3: Design of steel structures Part 1-5: General rules - Plated structural elements. Brussels: European Committee for Standardization (CEN), 2006. $55 \mathrm{p}$.

EN 1993-4-1: 2007 - Eurocode 3: Design of steel structures Part 4-1: Silos Eurocode 3. Brussels: European Committee for Standardization (CEN), 2007. $117 \mathrm{p}$.

Fernández, R. G.; García, C. P.; Lavína, A. G.; de las Hera, J. L. B.; Pis, J. J. 2013. Influence of physical properties of solid biomass fuels on the design and cost of storage installations, Waste Management 33(5): 1151-1157. http://dx.doi.org/10.1016/j.wasman.2013.01.033

Gallego, E.; González-Montellano, C.; Ramírez, A.; Ayuga, F. 2011. A simplified analytical procedure for assessing the worst patch load location on circular steel silos with corrugated walls, Engineering Structures 33(6): 1940-1954. http://dx.doi.org/10.1016/j.engstruct.2011.02.032

Horabik, J. 2001. Characterization of physical properties of bulk materials, having bearing on storage processes, Acta Agrophysica 54. 121 p. (in Polish).

Hotała, E. 2003. Ultimate load-bearing capacity of unribbed cylindrical shells of steel silos. Wrocław: Wrocław University of Technology Publishing House. 115 p. (in Polish).

Hotała, E.; Kuśnierek, M. 2013. Laboratory test upon chosen properties of biomass stored in silos, Materiaty Budowlane 3: 57-59 (in Polish).

Jensen, P. D.; Mattsson, J. E.; Kofman, P. D.; Klausner, A. 2004. Tendency of wood fuels from whole trees, logging residues and roundwood to bridge over openings, Biomass \& Bioenergy 26(2): 107-113. http://dx.doi.org/10.1016/S0961-9534(03)00101-6

Larsson, S. H.; Lestander, T. A.; Crompton, D.; Melin, S.; Sokhansanj, S. 2012. Temperature patterns in large scale wood pellet silo storage, Applied Energy 92: 322-327. http://dx.doi.org/10.1016/j.apenergy.2011.11.012

Mattsson, J. E. 1990. Basic handling characteristics of wood fuels: angle of repose, friction against surfaces and tendency to bridge for different assortments, Scandinavian Journal of Forest Research 5(1-4): 583-597. http://dx.doi.org/10.1080/02827589009382641
Miccio, F.; Barletta, D.; Poletto, M. 2013. Flow properties and arching behaviour of biomass particulate solids, Powder Technology 235: 312-321. http://dx.doi.org/10.1016/j.powtec.2012.10.047

Nothdurft, H. 1975. Schüttgutlasten in Silozellen mit Querschnittsverengungen: Dissertation. Braunschweig: TU Braunschweig (in German).

Oveisi, E.; Lau, A.; Sokhansanj, S.; Lim, C. J.; Bi, X.; Larsson, S. H.; Melin, S. 2013. Breakage behaviour of wood pellets due to free fall, Powder Technology 235: 493-499. http://dx.doi.org/10.1016/j.powtec.2012.10.022

PN-B-03262: 2002 - Reinforced concrete silos for bulk materials. Static load calculations, design, execution and operation. Warsaw: Polish Committee for Standardization, 2002. 31 p. (in Polish).

PN-B-03202: 1996 - Steel constructions. Silos for bulk materials. Static load calculations and design. Warsaw: Polish Committee for Standardization, 1996. 52 p. (in Polish).

PN-EN 1991-4: 2006 - Eurocode 1. Impacts on structures. Part 4: Silos and tanks. Warsaw: Polish Committee for Standardization, 2006. $115 \mathrm{p}$.

Rotter, J. M. 2001. Guide for economic design of metal silos. Spon Press. 256 p. http://dx.doi.org/10.4324/9780203477816

Sadowski, A. J.; Rotter, J. M. 2010. Study of buckling in steel silos under eccentric discharge flows of stored solids, Journal of Engineering Mechanics 136(6): 769-776. http://dx.doi.org/10.1061/(ASCE)EM.1943-7889.0000112

Sadowski, A. J.; Rotter, J. M. 2011. Buckling of very slender metal silos under eccentric discharge, Engineering Structures 33(4): 1187-1194. http://dx.doi.org/10.1016/j.engstruct.2010.12.040

Sadowski, A. J.; Rotter, J. M. 2012. Structural behaviour of thin-walled metal silos subject to different flow channel sizes under eccentric discharge pressures, Journal of Structural Engineering 138(7): 922-931. http://dx.doi.org/10.1061/(ASCE)ST.1943-541X.0000530

Skonecki, S.; Gawłowski, S.; Potręć, M.; Laskowski, J. 2011a. Physical and chemical properties of plant raw materials used in production of biofuels, Inżynieria Rolnicza 8: 253-260 (in Polish).

Skonecki, S.; Potręć, M.; Laskowski, J. 2011b. Physical and chemical properties of agricultural wastes, Acta Agrophysica 18(2): 443-455 (in Polish).

Walker, D. M. 1966. An approximate theory for pressure and arching in hoppers, Chemical Engineering Science 21(11): 975-997. http://dx.doi.org/10.1016/0009-2509(66)85095-9

Ryszard ANTONOWICZ. PhD, Senior Lecturer at Division of General Building of Institute of Building Engineering of Wroclaw University of Technology. The main research interests: experimental and theoretical studies on reinforced concrete and prestressed tanks for bulk solids, flow of bulk solids, limit states of timber structures and numerical modelling of building structures.

Czesław BYWALSKI. PhD, Senior Lecturer at Division of Concrete Structures of Institute of Building Engineering of Wroclaw University of Technology. The main research fields: experimental and theoretical studies on reinforced concrete, steel fibre reinforced concrete, prestressed tanks for bulk solids and liquids and numerical modelling of concrete structures.

Mieczysław KAMINSKI. Professor of Civil Engineering. Head of Division of Concrete Structures of Institute of Building Engineering of Wroclaw University of Technology. The main research interests: experimental and theoretical studies on reinforced concrete and prestressed tanks for bulk solids and liquids, cooling towers, limit states of reinforced and prestressedconcrete beams and inspection of real industrial structures. 